\title{
Effectiveness of taping for the prevention of ankle ligament sprains
}

\author{
P. Firer, MMed(Ortho) \\ Rosebank Knee and Sports Injury Clinic, South Africa
}

\begin{abstract}
The effectiveness of taping in the prevention of sports injuries has only been studied in detail with regard to the lateral ligaments of the ankle. It appears that taping can protect against injury. The mechanism by which taping works is not certain, but mechanical factors play a role which decreases with exercise. The major effect of taping may be its proprioceptive effect on underlying muscle groups.
\end{abstract}

Keywords: Ankle ligament sprains, prevention, taping

In assessing the effect of taping in the prevention of ankle injuries three questions must be considered. Is there scientific evidence that taping reduces the incidence or degree of injury? If there is evidence, what are the mechanisms by which taping works? Can taping be harmful by indirectly causing other injuries?

Cerney ${ }^{1}$ recommended taping as a support to protect against injury, to assist with healing, and to aid with rehabilitation for almost any part of the musculo-skeletal system. Hirata ${ }^{2}$ also prescribed taping for many anatomical sites.

However, scientific literature on taping is virtually exclusively based on the ankle joint. The probable reasons for this are that the lateral ligaments of the ankle are the most frequently injured in the athlete ${ }^{3}$; the joint is readily amenable to strapping techniques that may have mechanically limiting effect; it is the part most commonly taped prophylactically; and it is a joint in which movements are easily measured and in which the lateral ligaments come under strain toward the end of the range.

This article will review scientific evidence on the role of taping in the prevention of injury to the lateral ligaments of the ankle.

Address for correspondence: Dr Ponky Firer, Rosebank Knee and Sports Injury Clinic, 20 Medical and Dental Centre, 11 Sturdee Avenue, Rosebank 2196, South Africa

(C) 1990 Butterworth \& Co (Publishers) Ltd 0306-3674/90/010047-04

\section{Does taping reduce injury?}

Quigley et al. ${ }^{4}$ and Thorndike $^{5}$ were the earliest workers to show a reduction in ankle injuries when using prophylactic taping. Thorndike reported a minimum 50 per cent reduction in ankle injuries with taping for all matches and practices.

Garrick and Requa's ${ }^{6}$ study on injury rate in college intramural basketball players is the only significant work that used a control group of untaped players. A Gibney basketweave taping with heel-lock was used. Players were randomly assigned into taped or untaped groups. They used their usual high, or low, topped shoes, and were questioned about ankle sprains.

A total of 2562 player games were studied. There was a significant overall reduction in ankle sprain rates in the taped ankles compared to the untaped ankles. Taped ankles had an injury rate of 14.7 sprains $/ 1000$ player games, while untaped ankles had an injury rate of 32.8 sprains $/ 1000$ player games. There was a positive influence of the high topped shoe on the injury rate (Table 1), differential injury rates being:

High top shoe/taped Low top shoe/taped High top shoe/untaped Low top shoe/untaped

A Chi-square test applied to the frequency distribution underlying these rates yielded statistical significance at the $p=0,025$ level.

Garrick and Requa ${ }^{6}$ also looked at the injury rate of players with histories of previous ankle sprains. Overall those with a history of previous injury were about twice as likely to be injured as their counter-

Table 1. The influence of shoe design on the rate of injury in ankle sprains

Ankle sprains/1000 player games

\begin{tabular}{lcc}
\hline & High top & Low top \\
Taped & 6.5 & 17.6 \\
Untaped & 30.4 & 33.4 \\
\hline
\end{tabular}


parts (27.7 vs $13.9 / 1000$ player games) and these players gained increased protection from prophylactic taping (injury rate of $16.4 / 1000$ player games for taped players).

Two other trends emerged:

Elastic tape was used in 288 player games giving an injury rate of $6.9 / 1000$ player games. This suggests that elastic tape, which may not have the mechanical restriction of rigid tape as discussed later, may be equally effective in preventing ankle sprains.

The lower rate of knee injuries in the taped ankles compared to untaped ankles suggest that there is at least a probability that ankle taping does not have a deleterious effect on the knee joint.

Firer ${ }^{7}$ subjectively studied six provincial (state) level field hockey players with a history of recurrent ankle sprains. They had a minimum of three inversion injuries per season for at least two seasons. The injuries necessitated the player missing at least two or more practices and matches.

For the whole of the following season (April to September which included approximately 120 practices and matches) the players taped their ankles with an elastic adhesive tape in the Gibney basket-weave manner. There was only one inversion injury throughout the season, and the player only needed to miss one practice. All players reported an increased feeling of stability and confidence in the ankle.

This is not a statistically significant study and has no control group, but it is further confirmation that ankle taping could reduce recurrent injury in a high risk sports population. The trend was similar to the findings of Garrick and Requa ${ }^{6}$.

Tropp et al. prospectively studied ankle ligament injuries in Swedish football players ${ }^{8}$. Their subjects were divided into three groups; a control group; a second group who wore a semi-rigid support (Tropp et al. ${ }^{8}$ assumed the work of Hughes and Stetts ${ }^{9}$ which showed that taping and the semi-rigid support were equally effective in restricting ankle inversion); and a third group who did not wear a support but did functional proprioceptive exercises. Players with previous injuries showed a statistically significant increase in sprain rate compared to the control group. The mechanically supported and functionally trained groups had equally lower sprain rates.

Given the limited evidence available, taping has been shown to prevent injuries to the lateral ligaments of the ankle and that this is most significant in the previously injured ankle.

\section{What are the mechanisms by which taping works?}

\section{Mechanical stabilisation}

The majority on studies of taping to protect the ankle have studied its mechanical effects - either the decreased movement in inversion-plantarflexion (the sprain mechanism) with taping or the increased force required for a specific displacement in inversion and plantarflexion.

Mechanical testing can be done either with the ankle relaxed and passive movement applied or active by the subject's movements. Passive studies done by Rarick et al. ${ }^{10}$ tested the force required to invert and plantarflex the ankle joint to set displacement just short of maximum, the point at which taping might be most effective. Taped ankles and untaped ankles here compared with four different methods of support:

Basket-weave

Basket-weave with stirrup

Basket-weave and heel-lock

Basket-weave with a combination stirrup and heel-lock

The ankles were tested untaped both before and after ten minutes of vigorous exercise and Rarick's conclusions were that:

Taping does give significant mechanical resistance to an inversion plantarflexion force applied to the relaxed ankle

The net supporting force is reduced by as much as 40 per cent after ten minutes of vigorous exercise Different methods of taping varied in their support, with the basket-weave with combined stirrup and heel-lock having the greatest effect and the plain basket-weave the least.

The authors noted that at the end of each test the testing procedure had either loosened or torn the tape, or displaced the whole strapping downwards on the leg. Thus, the adhesiveness or strength of the tape was not strong enough to withstand the testing procedure.

In contrast to the normal ankles tested by Rarick ${ }^{10}$, further passive studies were done by Larsen ${ }^{11}$ on 20 patients with chronic ankle instability. He measured the degree of anterior drawer and talar tilt radiologically before taping, after taping and 20 minutes of stop-start and uneven ground running with tape. An applied constant force was used to invert and plantarflex the ankle. He found:

A significant diminution in degree of radiological displacement after taping

The higher the displacement untaped, the greater the percentage improvement after taping

After exercise the improvement in radiological displacement was lessened, but the improvement from the pre-taped readings was still significant, but only for the talar tilt measurements and not for the anterior drawer measurements.

Loosening of the tape was also noted after exercise in 19 of 20 subjects. All of these patients subsequently had surgery for chronic instability. This suggests that for chronic radiological instability in patients with functional instability, taping could reduce the degree of talar tilt to a fixed inverting force. This reduction was lessened by exercise. The mechanical effect in this group of patients can be assumed not to have reduced the functional instability as they all required surgery for persistent symptoms.

Ankle stability has also been tested in active situations. Laughman et al. ${ }^{12}$ studied the degree of ankle mobility in subjects when walking on an inclined plane sideways i.e. stressing the ankle in inversion or eversion. Electrogoniometer measurements were done on pre-taped and post-taped subjects pre- and post-exercise. Exercise was fairly vigorous figure-eight running for 15 minutes. 
A significant decrease (26.7 per cent) in ankle inversion-plantarflexion was found between the untaped and taped pre-exercise ankles. The tape did loosen after exercise and the pre-taped to post-taped post-exercise reduction in movement averaged 18.6 per cent. The authors point out that not only was single plane inversion limited but some of the effect was to reduce single plane plantarflexion. Fumich et $a l .{ }^{13}$ and Myburgh et al. ${ }^{14}$, using the measurement technique of Fumich, measured the range of movement the ankle could undergo actively before taping, after taping and after taping and exercise. The ankles were strapped into a goniometer and the subjects actively placed their ankles in the required positions of maximum displacements.

Fumich et al. ${ }^{13}$ studied players who were taped with a rigid tape and exercised for three hours during an American football practice. They showed that there was a statistically significant reduction in all ankle movements immediately after taping. This reduction in movement was lessened (indicating tape loosening) after exercise. Those movements still showing a residual restriction after exercise of 50 per cent or greater than the initial restriction before exercise were inversion in neutral and inversion in plantarflexion.

The greatest absolute degree of restriction with tape before exercise occurred for plantarflexion, plantarflexion-inversion and inversion neutral, which are the movements that taping is supposed to restrict to prevent ankle injury. The actual restriction found was $4^{\circ}$ after exercise from the pre-taped level for plantarflexion; a $6.38^{\circ}$ restriction for inversion in neutral; and a $5.81^{\circ}$ restriction for plantarflexion in inversion. These were statistically significant.

The Myburgh et al. ${ }^{14}$ study looked at the various types of support given by an elasticised commercially made ankle guard, a non-stretch tape and an elastic tape. The right foot of each patient was measured untaped, taped pre-exercise, taped after ten minutes of exercise, and taped after one hour of exercise. The left feet were measured unsupported and remained unsupported during exercise as a control. The exercise used was a vigorous game of squash against players of an equivalent standard.

Their findings indicated that the elasticated commercially made ankle guard did not provide any significant support for any of the movements measured which were the same movements measured by Fumich et al. ${ }^{13}$ This lack of support occurred both before and after exercise.

The non-elastic tapes had a significant effect in decreasing plantarflexion and inversion movements both before and after ten minutes of exercise, but after one hour's exercise there was no reduction in these movements compared to the untaped ankles. Thus maximum loosening did not occur in the first ten minutes of this particular type of exercise, but occurred somewhere between 10 and 60 minutes.

Comparing overall results of Myburgh $^{14}$ and Fumich ${ }^{13}$ it is noted that both found a 30 per cent decrease in the ankle's active range of motion directly after the application of tape. However, the Fumich group found the restriction reduced to 15 per cent after three hours of American football practice, whereas Myburgh's group found the restriction reduced to 10 per cent after one hour of squash. This difference may be ascribed to the greater stress applied to an ankle during a continuous squash game, as opposed to the intermittent activity of a football practice.

Thus the mechanical effect of taping ankles appears to be one of restriction of movement at the extreme ranges with reduction of abnormal movements which occur during injury. This effect lessens significantly with the type and duration of exercise. The effect is lost after a period of intense activity.

The force required to sprain the lateral ligaments of the ankle is unknown. It is probably far greater than the forces used to passively displace the ankle or the subject's active forces of displacement used in the studies quoted above. There is thus considerable doubt that taping can mechanically support an ankle undergoing the force required for ligament rupture and so dissipate this force away from the ligament. This is of especial concern after intense exercise and needs further study.

\section{Proprioceptive stimulation}

Thus, evidence exists that taping can reduce the incidence of ankle injury in sports. If the effect is not entirely mechanical some other mechanism must be in force.

Freeman ${ }^{15}$ has stated that proprioceptive rehabilitation is the treatment of choice for lateral ligament injuries of the ankle, functional stability rather than mechanical stability being the aim. Tropp et al. ${ }^{8}$ showed that proprioceptive training was as effective as taping in the reduction of ankle injuries. Bosien $e t$ $a l .{ }^{16}$ found that 22 per cent of unstable ankles studied had weakness of the peroneal muscles.

My personal observation is that the majority of ankle sprains occur when the player heel-strikes in an extensive amount of inversion. This is aggravated by poor shoes and poor field-surface conditions. It would seem that improving the activity of the peroneus muscle may prevent ankle ligament injury.

Glick et al. ${ }^{17}$ having shown the failure of taping to support the ankle mechanically after exercise, studied the effect of taping on the action of peroneus brevis during the running cycle using simultaneous electromyography and stop-action movies. They noted that just before heel-strike the foot was in various degrees of inversion.

In three out of four subjects, with significant talar tilt, it was noticed that the peroneus brevis started to contract just before the end of the swing phase of the cycle, i.e. it was coming into action just before heel-strike to attempt to correct the position of inversion and stabilise the ankle and foot. One individual with a significant talar tilt had no contraction of the peroneus brevis muscle at the end of the swing phase in gait.

When the ankles were taped in three of the four subjects with significant talar tilt, the peroneus brevis muscle functioned for a longer period during the end of the swing phase. This study would suggest that, at least in mechanically unstable ankles, taping may stimulate the peroneus brevis muscle to come into 
action earlier and thus have a beneficial effect in everting the ankle earlier in the gait phase and so prevent inversion injury of the ankle.

In summary, it would appear from the evidence available that taping may have an effect in mechanically stabilising the ankle joint up to a point and for a limited exercise time only. Possibly the most important effect is its proprioceptive stimulating effect on the peroneus brevis.

\section{Can taping indirectly cause other injuries?}

Ferguson ${ }^{18}$ and Hirata ${ }^{2}$ questioned the possibility of increased knee injuries in taped ankles. Glick et al. ${ }^{17}$ and Garrick and Requa ${ }^{6}$ independently found that taping did not increase the incidence of knee injuries. There is no other scientific work that has shown that taping in any way weakens any part or increases injury at any other site of the body.

\section{Conclusions}

Ankle taping plays a role in the prevention of injuries to the lateral ligaments of the ankle. Adequate scientific studies on the effect of taping of muscles and other areas, for example knee ligaments and shoulders, are lacking.

An interview with any number of athletes, trainers, coaches and sports medicine physicians, especially in North America, would persuade one that taping is essential. One can conclude that taping probably has more than a psychological effect in the prevention of injury.

Mechanical support of the ankle is possible for only short periods of exercise. It is unlikely that a hamstring or knee ligament could be mechanically supported for any significant time to prevent injury by limiting movement.

If taping works elsewhere in the body, then it would most likely be because of proprioceptive stimulation of normal neuro-muscular mechanisms that protect against injurious movement. This would mean that rigid tape was not essential and that elasticated tape may be equally or even more effective. Elasticised tape has been shown to give a better subjective feeling of stability and comfort with minimal loosening.

There is much work required to explain the decades of acceptance that taping is an essential part of sports medicine.

\section{References}

1 Cerney, J.V. 'Complete book of athletic taping techniques' Parker Publishing Company, West Nyack, New York, 1972

2 Hirata, I. 'The doctor and the athlete' Second edition, JB Lippincott Company, Philadelphia, 1974, 252-272

3 Garrick, J.G. The frequency of injury, mechanism of injury and epidemiology of ankle sprains American Journal of Sports Medicine 1977, 5, 241-242

4 Quigley, T.B., Cox, J. and Murphy, J. Protective device for the ankle Journal of the American Medical Association 1946, 123, 924

5 Thorndike, A.J. 'Athletic injuries: Prevention, diagnosis and treatment' Philadelphia, Lea and Febiger, 1956, 56-60

6 Garrick, J.G. and Requa, R.K. Role of external support in the prevention of ankle sprains Medicine and Science in Sports 1973, 5, 200-203

7 Firer, P. Taping the lateral ligaments of the ankle South African Sports Medicine 1980, 4, 7-8

8 Tropp, H., Askling, C. and Gillquist, J. Prevention of ankle sprains The American Journal of Sports Medicine 1985, 13, 259-262

9 Hughes, L.H. and Stetts, D.M. A comparison of ankle taping and a semi-rigid support The Physician and Sports Medicine 1983, 11(4). 99-103

10 Rarick, G.L., Bigley, G., Karst, R. and Malina, R.M. The measurable support of the ankle joint by conventional methods of taping Journal of Bone and Joint Surgery 1962, 44, 1183-1190

11 Larsen, E. Taping the ankle of chronic instability Acta Orthopaedica Scandinavica 1984, 55, 551-553

12 Laughman, R.K., Carr, T.A., Chao, E.Y., Youdas, J.W. and Sim, F. Three-dimensional kinematics of the taped ankle before and after exercise American Journal of Sports Medicine 1980, 66, 425-431

13 Fumich, R.M., Ellison, A.E., Geurin, G.J. and Grace, P.D. The measured effect of taping on combined foot and ankle motion before and after exercise American Journal of Sports Medicine 1981, 9, 165-170

14 Myburgh, K.H., Baughan, C.L. and Isaacs, S.K. The effects of ankle guards and taping on joint motion before, during and after a squash match American Journal of Sports Medicine 1984, 12, 441-446

15 Freeman, M.A.R. Treatment of ruptures of lateral ligaments of the ankle Journal of Bone and Joint Surgery 1965, 47B, 661-668

16 Bosien, W.R., Staples, A.S. and Russel, S.W. Residual disability following acute ankle sprain Journal of Bone and Joint Surgery 1955, 37A, 1237-1243

17 Glick, J.M., Gordon, R.B. and Nishimoto, D. The prevention and treatment of ankle injuries American Journal of Sports Medicine 1976, 4, 13-141

18 Ferguson, A.B. The case against ankle taping Sports Medicine 1973, 1, 46-47 